\section{Supporting entrepreneurship students' sense of belonging in online virtual spaces}

\author{
Jacqueline Brodie $\mathbb{D}$ and Renata Osowska \\ Edinburgh Napier University, UK
}

Industry and Higher Education 202I, Vol. 35(4) 353-359 (c) The Author(s) 2021

Article reuse guidelines: sagepub.com/journals-permissions DOI: $10.1177 / 0950422221999264$ journals.sagepub.com/home/ihe

\begin{abstract}
Universities globally are aspiring to grow through investing in the delivery of online learning programmes. However, the attrition rate for online learning is high. It has been noted that those students with a sense of belonging to their course experience increased enjoyment and reduced anxiety and are therefore less likely to withdraw. Yet too often programme design guidance to support a sense of belonging for student communities focuses on localised, full-time and young students rather than older, globally dispersed, time-starved students such as those in the online entrepreneurship programme that is the subject of this paper. The authors explore how a sense of belonging in entrepreneurship students can be supported effectively in a virtual learning space throughout their online degree studies. The research presented adopts an interpretivist perspective and includes interviews with eight students studying a I-year top-up degree in a UK higher education institution. The teaching and support staff interviewed were based solely in the UK. The data collected were examined using thematic analysis. The paper contributes to the debate about what a sense of belonging means in a virtual space for entrepreneurship students and identifies how such students can feel connected and supported to finish their course.
\end{abstract}

\title{
Keywords
}

Belonging, entrepreneurship education, online learning, student retention

Before 2020 many higher education institutions were looking to launch and grow online programmes to support sustainable growth of their educational offering (Garrison, 2017). This imperative has only increased since the onset of the coronavirus pandemic. However, despite the worldwide growth in online programmes, the attrition rate for online learning has remained high (Boton and Gregory, 2015). Thomas et al. (2014) noted that those students with a sense of belonging to their course experienced increased enjoyment and reduced anxiety and were less likely to withdraw from their course. However, too often programme design guidance on supporting a sense of belonging in student communities has focused on localised, full-time and young students (Siivonen et al., 2019), rather than the older, geographically dispersed, time-starved students in our online entrepreneurship programme. There is also diversity in expectations and needs at different stages in an online student's academic journey, and this requires closer scrutiny than is currently provided in the literature if we are to achieve our collective aspiration, as entrepreneurship educators, to support the growth of globally connected innovative communities that are ultimately self-sustaining beyond graduation.
We have written previously about our campus-based 1-year enterprise top-up degree and its role in widening access to those who can benefit from higher education while aiming to 'deliver high-quality and leading-edge learner-centred approaches to learning, teaching and assessment and learner support' (Brodie et al., 2009: 234). More than a decade later, this course is still running successfully. Moreover, given its appeal to a variety of types of student, it has now been extended to offer an online version that is delivered globally. This development, however, required changes to the pedagogy and a different set of skills on the part of those supporting the students (Moore et al., 2011). This paper adds to the debate about the role of belonging by discussing the research findings of a project that explored how students participating in the online version of the programme were perceiving their learning experiences and how tutors and support staff were actively

\section{Corresponding author:}

Jacqueline Brodie, The Business School, Edinburgh Napier University, Edinburgh EHI4 IDJ, UK.

Email: j.brodie@napier.ac.uk 
supporting their sense of belonging. We conclude by considering opportunities to enhance that sense of belonging for such a diverse cohort of entrepreneurship students.

\section{Developing a sense of belonging in online spaces}

A 'sense of belonging' in this context can be taken to refer to a student's sense that they are connected to their studies and that their presence and involvement matters to their peers and educators (cf. Peacock et al., 2019). Previous research has told us that, if we do not seek to foster a sense of belonging, students may see themselves as 'other' or as disenfranchised (Read et al., 2003). Furthermore, it has been noted that non-traditional students often have 'less confidence in the personal and career relevance of higher education' and have been found to 'experience alienation from the cultures of universities' (James et al., 2008: 3). This alienation and dissatisfaction can be intensified if students are not campus-based (Exter et al., 2009). Supporting a sense of belonging appears, therefore, to be critically important in ensuring that online students persist and succeed at university (Thomas et al., 2014). However, recognition of the importance of this support raises the challenge of how to do it successfully.

Two means of achieving this have been identified in the literature - exploring real-life case studies with students, and work-related learning (Araújo et al., 2015). Learning through these methods demands commitment and belonging. The use of case studies and work-related learning are key components of the 1-year top-up degree which is the subject of this paper, so it would be expected that they would be highlighted by learners in our research. Additionally, the literature identifies informal peer learning and active learning environments as means to foster belonging (Meeuwisse et al., 2010). As Tinto notes, 'Students who are actively involved in learning, that is, who spend more time on task, especially with others, are more likely to learn, and in turn, more likely to stay'. (Tinto, 2006: 3).

To support transitions in student learning, other key areas flagged in the literature are personal development planning, which makes up part of our work-based learning experience, designing assessments to span across a programme, such as in our work-based learning module, and allowing students to apply their feedback in one area to other areas - which is supported by the programme due to the integrated nature of the learning across different modules.

Another area suggested in the literature is the modelling of professional identity by academics through the use of professional language, the types of sources they cite and their attitudes to students. Furthermore, Garrison (2017) stressed the importance of student belonging in online communities of inquiry, where the role of the tutor in fostering a sense of belonging is indisputable but poses many challenges (Thomas et al., 2014).

Reflecting on the literature, then, two key questions arise: first, who are the actors involved in supporting a sense of belonging and how could it be better supported; and, second, what tools are the best to facilitate the process? These questions will be investigated in the case of an Enterprise Top-Up degree, as discussed below.

\section{Background to the enterprise top-up degree}

Despite the success of the 1-year online top-up programme, the teaching team wanted to explore how a sense of belonging was being actively fostered and whether more could be done in that regard. The online version of the top-up degree is an innovative programme that offers progression beyond SVQ level 4 or equivalent, to obtain a degree qualification. ${ }^{1}$ People who study on this programme are normally mature students in full-time employment, many based overseas in locations including the USA and the Caribbean. Therefore, the programme team has sought to create a delivery mode that is appropriate to the needs of this diverse student body and inculcates entrepreneurship and innovation throughout the programme (Thompson and Randall, 2001).

This programme offers a part-time flexible mode of delivery that enables students to complete their degreelevel study in 1 year, building on their previous study experience or work-based learning. Students can commence their studies at any of the three trimesters in the academic year and can begin on any module in the programme. The ability to offer more than one starting point for this top-up degree has been well received by both students and employers - although the programme team recognises the challenges this flexibility presents in terms of supporting a sense of belonging for students, especially within different cohorts, as they move through the programme.

The founding principle of the degree is to provide a university-based education emphasising enterprising and entrepreneurial approaches. The rationale behind the chosen modules is to achieve a focus on creativity, innovation, planning, and implementing and managing processes in organisations in an enterprising way. This combination enables students to develop management skills and to apply learning in a hands-on way through flexible assessments. The ability to 'cross-fertilise' ideas between subject areas is reinforced through the year-long work-based learning module.

The overall aim of the programme is to produce graduates who are capable of meeting a range of business and organisational needs - an ability they will have attained by learning through enterprise, a concept closely linked to enterprise education pedagogy as highlighted by Jones and Iredale (2010). By completion of the programme, students should be able to: (1) apply theoretical and practical 
Table I. Indicative module delivery schedule.

\begin{tabular}{ll}
\hline Induction & \\
\hline Trimester I & $\begin{array}{c}\text { Creativity, Innovation } \\
\text { and Enterprise } \\
\text { Business Processes }\end{array}$ \\
Trimester 2 & $\begin{array}{c}\text { Business Growth } \\
\text { Issues }\end{array}$ \\
$\begin{array}{l}\text { Undertaken at the same time as the } \\
\text { above modules over three trimesters }\end{array}$ & $\begin{array}{l}\text { Work Based Learning } \\
(60 \text { credits })\end{array}$ \\
\hline
\end{tabular}

Note: Students will normally complete the programme in one calendar year.

approaches to the development of businesses and organisations; (2) innovate and develop creative solutions to business/organisational issues; and (3) develop a portfolio of knowledge, skills and approaches appropriate to personal and business needs.

In designing the online programme several key issues were taken into account: ensuring an in-built flexibility (e.g. multiple start-points throughout the year, allowing the students to work at a pace that suits their own needs); wherever possible, offering a practical, hands-on approach; and continuing professional development (with students enhancing their personal approach to business in their work-based learning module).

These learning approaches used in the programme design relate closely to the programme structure, which is currently built around four separate entrepreneurshipfocused modules, comprising the 120 credits needed to complete the degree (see Table 1).

Delivery of the modules is done in a highly flexible way over the course of a calendar year, and the assessment process is in line with this flexibility. Students' complete project work, action research, portfolio building and reflective logs. In most instances, assessment takes into account application in the workplace or research focused on real-world problems. To support the students in creating connections with tutors and peers, monthly informal conversations with their programme leader are available, module tutors are available on a weekly basis to talk to them in online virtual spaces, and discussion boards are used throughout their studies to facilitate knowledge exchange and support. Informal peer support ('study buddy') also takes place and is encouraged by module teams. However, the students appear to prefer their own WhatsApp study groups instead.

\section{Methodology}

This study adopts an interpretivist perspective (Silverman, 1998) with qualitative data gathered through semistructured interviews, using open questions that elicited rich data from both students and other stakeholders (tutors on the programme and student support administrators). The semi-structured interviews offered guidance to the interviewer but also allowed the flexibility to change the course of the interview (Wilson, 2012). Selecting different types of respondents permitted a better understanding of the key actors' involvement and the assessment of tools facilitating the development of a sense of belonging from both the staff and student perspectives. The questions asked were tailored to the type of respondent, recognising different roles in programme delivery. The main themes focused on effective curriculum design and the design of learning spaces in the entrepreneurial classroom, and engagement in supporting online students' sense of belonging and the key relationships established during a student's journey.

The sample comprised 8 students from a year class of 42 in 2018/2019 who were self-selecting alongside two support staff and two tutors. The students interviewed ( 5 females, 3 male) were at different stages of their degree studies and were based in the UK or overseas. The two teaching and two support staff interviewed ( 3 female, 1 male) were based solely in the UK. The data were collected in person (for the teaching and support staff) and online via skype or telephone (for the students). A researcher who was not teaching the students undertook the data collection.

All interviews were recorded and later transcribed. The data collected were analysed using thematic analysis (Braun and Clarke, 2006) to identify key themes for further discussion. The thematic analysis process required the development of preliminary codes to highlight patterns in the data. The codes generated were sorted into potential themes and all data relevant to each potential theme were collated. Then the data were systematically reviewed to ensure that the emergent themes were appropriate. Participants were anonymised to ensure confidentiality and were given a relevant participant number. Ethical approval was obtained from the School's Ethics Committee. The ethical considerations for this study centred predominantly on issues of confidentiality and informed consent.

\section{Findings}

Three key themes emerged through the thematic analysis of the student interviews that can be used to help us think about effective curriculum design and the design of learning spaces in the entrepreneurial classroom. The first of these was the importance of making connections with the programme's academics and their support team. The data analysis highlighted that the students often felt more bonded with their online educators and support team than they did with their online peers, and that they relied on these individuals at specific times - such as when they were joining the course and when they were undertaking assessments. They particularly highlighted the tutor's availability and their own personal interactions with the instructors as beneficial: 
I did reach out to the Programme Leader [Name] ... really good...I keep on asking silly questions...I just thought... I'm the only one just asking you? (Student 3)

Where students felt that interaction with a tutor had not supported them enough, they had begun to reach out beyond the course and find themselves mentors in their own workplaces. Interestingly, there was much discussion about the relationship students had with the module leader of the workplace learning module spanning their three semesters, and how this individual had been a closer connection for them than their own programme leader, even though the programme leader had organised regular sessions for them to highlight programme issues. Few students attended these sessions because they either failed to see the value of such meetings for their own learning or were unable to identify any issues with the programme worth discussing at the meetings.

A second key theme that surfaced in the thematic analysis was the importance of peer interactions. Although these interactions could lead to stress when bonds were formed and then one student disappeared, in most cases bonds were sustained throughout the course. As noted by Student 3:

...just talking on the discussion board, but it was like talking to someone close to you because we got..., we both got kind of close because we tried ..., like the questions ..., she would just have some questions, or she would just be answering. So, it was quite encouraging as well.

Students explicitly stated that they often preferred to bond informally and formally with students in the same time zone as they were, perhaps, comforted by the cultural proximity:

Oh, definitely, I connected with persons from my own country ... You know, we chat to each other and everything. We have each other's cell phone number. I hope that once we're finished and we're able to graduate, that we'll be able to meet up, you know? (Student 4)

The above quotation highlights time zones as being a hindrance when trying to encourage students to support each other at the same stage of their studies. Despite being in different cohorts, geographical closeness overcame any other issues that could have arisen with students at different stages. Students were also keen to highlight that using informal tools like WhatsApp supported their learning and understanding in the online space.

A third key theme was that a sense of belonging was not always valued by the students. There is also confirmation, in the research findings, that some strategic learners actively choose to limit (or opt out of completely) the development of a sense of belonging when studying in the online classroom. Some students were quite comfortable getting on and doing it themselves (perhaps due to age, human capital and expectations of the online environment):

... But, you know, the process is really good, especially if you're a young student who has never been to university. I mean, I'm 46 [laughs], I've been around the block, and, yeah, I've been to 5 different universities now. So, I kind of know the process. (Student 1)

Such students felt that they could rely on themselves to achieve their learning goals and that reaching out for connections in their own workplace and securing themselves work-based mentors were more effective ways to navigate the course than spending time on the peer support discussion boards.

I . . feel supported from work ... I mean, my direct line boss, he's about 25 years younger than me, so I bypassed him and went to his boss, and so he knows that I'm doing this programme, and I spoke to one of the Directors of the company and he's my mentor. (Student 1)

Discussion boards, though traditionally used to create a sense of community (Lave and Wenger, 1991; Wenger, 1998), could also be viewed by students as reinforcing a sense of isolation if messages remained unanswered by peers. Another widely used communication tool, generic student email lists for student invitations/interventions (Dawson, 2006), made some distant learners feel disconnected or even overlooked by the university when the information was not relevant to them. Finally, awareness of social participation opportunities (student events) on campus appeared to create a sense of being 'different' in online students and this finding highlights the need for a more thoughtful management of communication in relation to distance learners.

\section{Supporting non-traditional students' sense of belonging: Staff reflections and recommendations}

In this section, we outline lessons learned by the teaching staff and support staff from their engagement in the support of online students on the programme and highlight the significant issues identified. From this information, we note opportunities for further refinement of the degree programme to further support the learning of these students.

One aspect noted by the teaching and support staff was the lack of non-academic activities on the programme. Both tutors highlighted the need for at least one assignment during the students' induction that would require them to work together in a fun, non-academic activity. This, they believed, would help break down some of the barriers between students in different locations, and their 
recommendation supports the importance of social engagement (Redmond et al., 2018) in an online context. To bond the students throughout the course the work-based learning (WBL) tutor also advocated brief but frequent interactions with students, enabling a deeper connection with the programme over the year:

I put a posting in the Moodle common room once a week. That gives people a sense of connection. I post a reading with a commentary every week, 45 readings associated with the ... module topics.

\section{Similarly the WBL tutor noted:}

I give them a lot of formative feedback on the work that they do... I am giving them personalised feedback once a month and telling them where they are with the course.

The tutors also noted the importance of giving control to the students concerning how they contacted them in the online environment. Having multiple contact points gave different types of learners different opportunities to connect (for example, email or joining weekly synchronous help sessions).

Both academics also identified the important role they played in acting as the focal point of the students' learning experiences and in modelling the professional values they wanted students to demonstrate in the workplace (thus reflecting the literature on personal identities and belonging). This point relates to the importance of the tutoring presence in promoting a sense of belonging (Peacock and Cowan, 2019). The academics noted, however, that a sense of belonging was valuable but was not always needed by certain types of students on the programme - again recognising the different strategic learning styles of the students (Liu, 2007).

Among the other areas that academic staff identified as in need of strengthening was peer mentoring - this is currently informal, but it was felt that it should be more formalised. One tutor noted that this could be linked to strengthening the programme's ties with alumni: they could be asked on graduating, 'Would you like to put something back? To be a mentor on the programme for the first three months or whatever?'

Both tutors confirmed the challenges of listening to the diverse voices on the programme and the work-based learning tutor recognised that students at different stages needed different support as they progressed through their studies. At the outset, there was a need for substantial scaffolding of concepts and 'guidance on how to learn', while towards the end of the programme the focus was on 'time management' and 'referencing practices'.

The support staff highlighted key areas with regard to instilling a sense of belonging. For example, some students expected that all the support services provided on campus would also be available to them but in some instances this was not the case; for example, students with IT problems were often asked to come to the campus for the support they needed when the online programmes started and this often led to frustration. While some students had clear expectations of what it would be like to be an online student, the support staff also noted that 'a lot of students just don't know what to expect' and 'need us to help them through those initial stages'. The support staff were investigating how to ensure that students had access to their induction site prior to joining the programme. This, they believed, would prevent them from feeling overwhelmed by the sheer volume of communications at the programme start.

The support staff also felt that more needed to be done at the programme level (rather than at module level) to ensure a deeper sense of belonging. They were exploring the introduction of a newsletter to inform students about updates to their programme, and a map application on their programme page so that they could share their location with fellow students. The support staff did note that there were already many places available for students to bond on the Enterprise Programme, such as the myriad of chat forums available and the virtual programme sessions but, without a Programme Leader who was viewed by the students as a 'strong presence' (i.e. highly visible), it was felt that students might not take up those opportunities. The support staff reflected that, when the programme was small, there had been a real sense of community and belonging because the students' only point of contact was one support person but, as the programme had grown and support had expanded, students were interacting with a range of support staff every time they contacted the support team. Finally, they also acknowledged, as did the tutors, that some students did not want a sense of belonging and were just interested in getting their qualification.

\section{Discussion}

Based on the interviews with participants, it seems that there is a difference of opinion concerning who plays a key role in creating belonging. However, all participants seemed to agree on the prerequisites and underlying conditions. Both staff and students highlighted the need for social engagement in the online space to create a sense of belonging in an online context (Redmond et al., 2018) based on a student's preferences and taking into account the student's individual approach to online education and level of maturity. Building a community in the online classroom is a vital aspect of online course design, so that there is a sense of belonging at times of stress and transition (Strayhorn, 2018). It is interesting, that online students still prefer 'to belong' in a spatial context, as is evidenced by the preferences for interacting within time zones.

Both staff and students also recognised the importance of the tutoring presence: it seems that designing an online 
course intentionally to build connections between students and with the instructor provides a sense of belonging (Peacock et al., 2019) and combats the sense of isolation that is inherent in distance learning (Kwon, 2010). Nevertheless, this bonding may take time to develop, due to the nature of the cohort, and hence the time spent with academics in this context is worth further research. There is, besides, diversity in expectations and needs at different stages in an online student's academic journey (Araujo et al., 2014; Hughes, 2007), which merits closer scrutiny than is currently provided in the literature, especially since individual needs for a sense of belonging may vary as a result (Peacock et al., 2019).

With regard to online tools, widely used automated messages either in the form of generic emails and university news seem to work against a sense of belonging among online students, making them, rather, feel disenfranchised (Read et al., 2003). This supports the argument that alienation and dissatisfaction can be intensified through a generic approach to communication if students are not campusbased (Exter et al., 2009). On the other hand, the introduction of student interaction in a non-academic context, more formalised peer mentoring and greater freedom in how students interact with academics may strengthen the sense of belonging.

Due to the exponential growth of the programme, which may lead to more issues arising from the scale and the different entry points in the year for cohorts on the programme, we intend to continue our research by interacting with current students on the programme to identify any additional areas that may need to be addressed in our efforts to engender a sense of belonging.

\section{Conclusion}

This paper aims to provide insight into how a sense of belonging can be supported in online virtual spaces with non-traditional entrepreneurship students. Our inquiry has sought to offer entrepreneurship educators new ideas on curriculum development, allowing students to remain in the workplace in highly-skilled jobs and yet still further their own enterprise learning to degree level with a sense of belonging to the online community. The study contributes to knowledge by providing further qualitative evidence of the key factors that affect the sense of belonging in a virtual space for entrepreneurship students and of the key touchpoints and connections that really matter to these learners when they are not based on campus. Finally, the work highlights the challenge of capturing the voices of online and distance learners to support curriculum development, and raises key questions about communication and engendering a sense of engagement at a distance in virtual spaces.

\section{Limitations and future research}

This study has certain limitations. First, we did not include longitudinal data since the goal of the research was a smallscale snapshot. Future studies could use longitudinal data to investigate the growth of a sense of community in greater detail, even if just to capture the year of study for the students or collect data from further cohorts. Second, the field of study should be expanded to a larger sample of participants and encompass students from a variety of different institutions.

Third, future studies in this field would do well to consider other participants - for example, instructors or students in different degree subjects guided by the entrepreneurial enterprise education pedagogy (this study focuses only on business students on a 1-year top-up degree.

Fourth, it would be interesting for future studies to explore further the use of academic tools provided by institutions as opposed to tools, such as WhatsApp, that students have adopted outside the traditional walled garden of learning management systems. Future research could be undertaken to improve our understanding of how a combination of both types of digital tools could be used to effectively support students and their sense of belonging or to identify which tools students prefer.

\section{Declaration of conflicting interests}

The author(s) declared no potential conflicts of interest with respect to the research, authorship, and/or publication of this article.

\section{Funding}

The author(s) received no financial support for the research, authorship, and/or publication of this article.

\section{ORCID iD}

Jacqueline Brodie (D) https://orcid.org/0000-0002-5404-7520

\section{Note}

1. SVQs are employment-based qualifications that provide the knowledge and skills needed for specific job roles and level 4 is seen as equivalent to 2 years of undergraduate study.

\section{References}

Araújo N, Carlin D, Clarke B, et al. (2014) Belonging in the first year: a creative discipline cohort case study. International Journal of the First Year in Higher Education 5(2): 21-31.

Araújo N, Wilson R and Clarke B (2015) Student engagement for employability: a belonging project case study. In: Thomas T, Levin E, Dawson P, Fraser K and Hadgraft R (eds) Research and Development in Higher Education: Learning for Life and Work in a Complex World 38: 1-10

Boton EC and Gregory S (2015) Minimizing attrition in online degree courses. Journal of Educators Online 12(1): 62-90. 
Braun V and Clarke V (2006) Using thematic analysis in psychology. Qualitative Research in Psychology 3: 77-101.

Brodie J, Laing S and Anderson M (2009) Developing enterprising people through an innovative enterprise degree: an analysis of the students' evolving perceptions and attitudes. Industry and Higher Education 23(3): 233-241.

Dawson S (2006) A study of the relationship between student communication interaction and sense of community. The Internet and Higher Education 9: 153-162.

Exter ME, Korkmaz N, Harlin NM, et al. (2009) Sense of community within a fully online program: perspectives of graduate students. Quarterly Review of Distance Education 10: 177-194.

Garrison DR (2017) E-Learning in the 21st Century: A Community of Inquiry Framework for Research and Practice, 3rd edn. New York, NY: Routledge.

Hughes G (2007) Diversity, identity and belonging in e-learning communities: some theories and paradoxes. Teaching in Higher Education 12: 709-720.

James R, Anderson A, Bexley E, Devlin M, Garnett R, Marginson S and Maxwell L (2008) Participation and equity: A review of the participation in higher education of people from low socioeconomic backgrounds and indigenous people. Report prepared for Universities Australia: Centre for the Study of Higher Education University of Melbourne.

Jones B and Iredale N (2010) Enterprise education as pedagogy. Education and Training 52(1): 7-19.

Kwon K, Han D, Bang EJ, et al. (2010) Feelings of isolation and coping mechanism in online learning environments: a case study of Asian international students. International Journal of Learning 17: 343-356.

Lave J and Wenger E (1991) Situated Learning: Legitimate Peripheral Participation. Cambridge: Cambridge University Press.

Liu X, Magjuka RJ, Bonk CJ, et al. (2007) Does sense of community matter? An examination of participants' perceptions of building learning communities in online courses. Quarterly Review of Distance Education 8: 9-22.

Meeuwisse M, Severiens SE and Born MP (2010) Learning environment, interaction, sense of belonging and study success in ethnically diverse student groups. Research in Higher Education 51: 528-545.
Moore JL, Dickson-Deane C and Galyen K (2011) E-learning, online learning, and distance learning environments: Are they the same? The Internet and Higher Education 14(2): 129-135.

Peacock S and Cowan J (2019) Promoting sense of belonging in online learning communities of inquiry in accredited courses. Online Learning 23(2): 67-81.

Peacock S, Cowan J, Irvine L, et al. (2019) An exploration into the importance of a sense of belonging for online learners. International Review of Research in Open and Distributed Learning 21(2): 18-35.

Read B, Archer L and Leathwood C (2003) Challenging cultures? Student conceptions of 'belonging' and 'isolation' at a post 1992 university. Studies in Higher Education 28(3): 261-277.

Redmond P, Abawi LA, Brown A, et al. (2018) An online engagement framework for higher education. Online Learning 22(1): 183-204.

Siivonen PT, Peura K, Hytti U, et al. (2019) The construction and regulation of collective entrepreneurial identity in student entrepreneurship societies. International Journal of Entrepreneurial Behavior \& Research 26(3): 521-538.

Silverman D (1998) Qualitative research: meanings or practices? Information Systems Journal 8(1): 3-20.

Strayhorn TL (2018) College Students' Sense of Belonging: A Key to Educational Success for All Students. New York, NY: Routledge.

Tinto V (2006) Taking Student Retention Seriously. Syracuse, NY: Syracuse University.

Thomas L, Herbert J and Teras M (2014) A sense of belonging to enhance participation, success and retention in online programs. The International Journal of the First Year in Higher Education 5(2): 69-80.

Thompson P and Randall B (2001) Can e-learning spur creativity, innovation and entrepreneurship? Educational Media International 38(4): 289-292.

Wenger E (1998) Communities of Practice: Learning, Meaning and Identity. Cambridge: Cambridge University Press.

Wilson V (2012) Research methods: interviews. Evidence Based Library and Information Practice 7(2): 96-98. 